\title{
An analysis of the framings of water scarcity in the Jordanian National Water Strategy
}

\section{Introduction}

This article investigates the two versions of the Jordanian national water strategy - the 2008-2022 and the 2016-2025 ones - focusing on how the issue of water scarcity is framed, and on the solutions suggested. This article analyses mainly the 2008-2022 version of the strategy, as it allows consideration of how it has been implemented. This article makes an original contribution to the literature of hydropolitics, as the Jordanian national water strategy has been overlooked by the literature, and its analysis would show the interplay between discourses of scarcities and policysolutions. By understanding the role of discourses and framings in the Jordanian national water strategies, policy makers will be better informed on the range of possible solutions and on how to solve water scarcity.

The 2008-2022 national water strategy "Water for Life," which was published in May 2009 by the Ministry of Water and Irrigation of Jordan, was commissioned by the king in February 2008 and prepared by the royal water committee. This committee was chaired by Prince Faisal and brings together ministries and non-governmental water professionals from different sectors. Specifically, the members of the royal water committee are: the ministers of water and irrigation, agriculture and environment, along with the director of the Economic Department at the Royal Court, Bishr Jardaneh, Suleiman Ghzawi, Ayman Bani Hani, Abdullah Malkawi, Elias Salameh, Tareq Abu Dueis, and Raed Zreikat. The strategy "establishes [the country's] Vision for each of the major areas of the Water Sector. It also establishes the Actions required to achieve the Visions [...] for the years up to 2022," as explained by Prince Faisal, Head of the Royal Water Committee (MWI, 2009: 1). The "Water for Life" (WfL) 2008-2022 strategy was updated in 2015, and is today known as the 2016-2025 national water strategy. The need for updating the strategy was due mainly to the subsequent turn of events, which were necessitated predominantly by the Syrian refugee crisis, and a need to revaluate future water needs and projections of population growth, which are incorporated in the updated report.

The main guiding question of this article is: How is water scarcity framed in the Jordanian water strategy, what are the causes emphasised, and what are the solutions identified? The article also attempts to understand: How has this framing changed in 
the two versions of the national water strategy? Building on Dryzek's understanding of a discourse as a "shared way of apprehending the world" (1997: 8), a discourse is defined - for the purpose of this article - as the representation and understanding of an issue reflected in the practices of an institution; hence it is not the mere declaration of a representative of said institution - as this could be an expression of a personal of opinion - but it is the shared way of understanding and practicing the world by the institution, as reflected in the institutional practices - for instance in reports, policies, strategies, and visions.

\section{The "Water for Life" 2008-2022 national water strategy}

This section analyses the causes for water scarcity emerging in the national water strategy against the following seven causes ${ }^{1}$ :

1) Population growth, immigration, and refugees;

2) Unfair water sharing with neighbouring countries;

3) Climate change as an additional pressure;

4) Low precipitation and aridity of the region;

5) Non-revenue water (NRW) due to leakages and physical losses;

6) NRW due to illegal wells and illegal use;

7) Unsustainable agricultural water use;

The WfL strategy for 2008 - 2022 is very comprehensive: it mentions all seven causes, not silencing any of them. First, it discusses population growth, immigration, and refugees several times in the strategy, for instance: "more pressure [...] from changes in population, household formation and development, and lifestyle" (MWI, 2009: 1-1); and "the future challenges on water demand are enormous. Any unexpected growth due to regional instability, as was the case during the past decades, would increase water demand and impact the plans to reach a balanced demand and supply" (MWI, 2009: 2-2). Second, the unfair sharing with neighbouring countries is also seen as contributing to water scarcity, and therefore "Jordan shall protect and defend the rightful shares of the Kingdom's water resources through bilateral and multilateral contacts, negotiations, and agreements" (MWI, 2009: 3-9). A goal for 2022 is to ensure that "our shared water rights are protected" (MWI, 2009: 3-3; 8-3). Third, climate change is seen as a adding a pressure on the water resources: "climate 
change scenarios all predict a further decline of our water resources" (MWI, 2009: 71). Fourth, water scarcity is seen as due to aridity and semi-aridity and the low precipitation resulting in the fact that "Jordan is one of the fourth driest countries in the World" (MWI, 2009: 2-1). Fifth, NRW due to leakages and physical losses is seen as a cause of water scarcity in a country where "non-revenue water is over $50 \%$ in much of the country" (MWI, 2009: 4-1; 8-3). Sixth, the strategy notes that NRW due to illegal wells and illegal use is part of the problem as "there are hundreds of illegal wells" (MWI, 2009: 2-1). Seventh, unsustainable agricultural water use is tackled in several parts of the strategy: "water for irrigation utilizes $71 \%$ of the water demand (2007) and 64\% of water supply (2007)" (MWI, 2009: 2-1); water scarcity is "manifested by a substantial imbalance in the foreign trade in food commodities" (MWI, 2009: 5-1) and a future challenge is that "irrigation consumes more than $64 \%$ (2007) of the total water used in Jordan while Agriculture's share of the GDP is 3\%" and there is a need for "irrigated agriculture in the highlands will need to be capped and regulated and the by-laws will need to be reinforced" (MWI, 2009: 5-2). As often highlighted by personnel of the ministry of agriculture, it must be said that there is dispute within Jordan on agricultural economic contribution. While official figures do say it is around $3 \%$, certain agricultural processes are counted as "industry" (e.g. olive oil production), meaning that some argue the $3 \%$ is artificially lowered. Also associated industries including transport, packing etc. means that a much larger proportion of the economy is agriculturally dependent. These indirect effects are important and used by the agricultural sector to justify continued water inputs and support by government, together with non-measurable social and environmental consequences of agriculture.

Table 1: Causes and solutions of water scarcity in the Jordanian government's "Water for Life" strategy

\begin{tabular}{|l|l|l|}
\hline \multicolumn{1}{|c|}{ Causes } & \multicolumn{1}{|c|}{ Suggested solutions } & \multicolumn{1}{c|}{$\begin{array}{c}\text { Demand - supply side } \\
\text { solution }\end{array}$} \\
\hline $\begin{array}{l}\text { Population growth, } \\
\text { immigration, and refugees }\end{array}$ & $\begin{array}{l}\text { RSDSC and non-conventional } \\
\text { water resources }\end{array}$ & Supply \\
\hline $\begin{array}{l}\text { Jordan as an arid / semi-arid } \\
\text { region with low precipitation }\end{array}$ & $\begin{array}{l}\text { RSDSC, Disi project, and non- } \\
\text { conventional water resources }\end{array}$ & Supply \\
\hline Unfair sharing with & Protect the Jordanian rights' & Supply \\
\hline
\end{tabular}




\begin{tabular}{|l|l|l|}
\hline neighbouring countries & $\begin{array}{l}\text { share; support negotiations, } \\
\text { agreements, and regional } \\
\text { cooperation for new water } \\
\text { resources }\end{array}$ & \\
\hline $\begin{array}{l}\text { Climate change as an } \\
\text { additional pressure }\end{array}$ & $\begin{array}{l}\text { RSDSC and non-conventional } \\
\text { water resources }\end{array}$ & Supply \\
\hline Nhysical losses & $\begin{array}{l}\text { Rehabilitation of the system and } \\
\text { increase efficiency in the water } \\
\text { utilities by involving the private } \\
\text { sector and institutional reform }\end{array}$ & Demand \\
\hline $\begin{array}{l}\text { NRW due to illegal wells and } \\
\text { illegal uses }\end{array}$ & $\begin{array}{l}\text { Implement existing regulations; } \\
\text { awareness raising }\end{array}$ & Demand \\
\hline Unsustainable agricultural & $\begin{array}{l}\text { Regulations on crops; eliminate } \\
\text { subsidies; tariffing schemes; water } \\
\text { water use }\end{array}$ & $\begin{array}{l}\text { Demand } \\
\text { raising associations; awareness }\end{array}$ \\
\hline
\end{tabular}

As shown in Table 1, the WfL strategy considers and mentions all the seven discourses. Constructing and reproducing the issue of water scarcity as due to all seven causes, it is unsurprising to find that the solutions and actions suggested are also comprehensive, including solutions on both the supply and the demand side. On the supply side, first the RSDSC and Disi projects are seen as strategic to obtain a demand-supply balance by 2022 (MWI, 2009: 1-4 - 1-7). In the opening statement of the former minister of the Ministry of Water and Irrigation (MWI) Raed Abu Saud, "We are taking on board serious important plans. By 2022, the Disi water conveyance and the Red-Dead Canal would be operational" (MWI, 2009: 2). Also, in the executive summary, it is emphasised that "in order to achieve the visions of this Water Strategy, the implementation are set under the following main themes: [...] implementation of the Disi water conveyance and the Red Dead conveyance projects" (MWI, 2009: 1-2). Second, new dams as well as works to enhance the storage of dams are planned (MWI, 2009: 3-3). Third, concerning non-conventional water resources, chapter six of the WfL strategy is dedicated to the issue of wastewater resources and treated wastewater for irrigational use: "Jordan will continue expanding 
the use of treated wastewater, which shows great potential for agriculture, industry, and urban landscape" (MWI, 2009: 2-5). Given the prospected population growth, “about 247 MCM [Million Cubic Meters] per year of wastewater is expected to be generated. When treated properly this water can be used for non-drinking purposes and will thus represent an important water resource for the country" (MWI, 2009: 61). Mainly due to the RSDSC project, in 2022 "water supply from desalination is a major source" of water supply (MWI, 2009: 3-3). "Jordan will implement regulations (incentives structures) to encourage rainwater harvesting" (MWI, 2009: 2-5), and the goal for 2022 is that in Jordan "rainwater harvesting is encouraged and promoted" (MWI, 2009: 7-2). Finally, also claiming and increasing the Jordanian share rights on transboundary water resources is among the solutions suggested by the strategy (MWI, 2009: 3-9).

Until here, the supply side solutions have been illustrated. However, solutions from the demand side are also promoted in the WfL strategy. First, NRW is aimed at being reduced by 2022 through rehabilitation of the supply system. This emerges in the water demand chapter: "we will reduce non-revenue water to $25 \%$ by 2022 with technical losses below $15 \%$. To reach this goal will require the rehabilitation of water supply systems (including improved water meters), optimization of operation and management, and network restructuring" (MWI, 2009: 2-6). Second, when discussing solutions on how to reduce NRW and making the supply system more efficient to reduce water scarcity, the strategy blames the public water utilities and calls for institutional reform and more involvement of the private sector (MWI, 2009: 4-5). In addition, expanding the role of the private sector and its participation in the management and ownership of the water utilities is strongly supported (MWI, 2009: 4-6). A chapter on institutional reforms focuses on this issue. This chapter identifies "weaknesses which require institutional reform" in the public sector, which "impedes efficient management" (MWI, 2009: 4-1). Among those challenges, overstaffing of the MWI, WAJ, and JVA and lack of stakeholders' involvement are mentioned (ibid.). As goals for 2022, "governance functions and operational functions are separated" and "commercial principles drive water management" are in place (MWI, 2009: 4-2). By 2022, "the retail function [...] will be privatized and/or handled by empowered farmers' associations" (MWI, 2009: 5-2). Third, the issue of tariffing schemes in the water sector is also promoted to promote water efficiency in irrigation by 2022 (MWI, 2009: 2-2). Tariff setting mechanism in order to reflect the "real value 
of water" will be taken, as low tariffs are seen to encourage waste and low-value uses, providing no incentive for efficient water distribution and use by water utilities and customers (MWI, 2009: 2-5). Fourth, the strategy argues that one solution should be on the agricultural and type of crops side. Market measures to discourage planting of crops with high water requirements, also through higher water tariffs for the agricultural sector and crops permits in line with water scarcity considerations, will be deployed (MWI, 2009: 5-4). Finally, raising awareness for behavioural change is seen as a necessary tool for solving water scarcity. "We will create awareness among the Jordanian public and decision makers as it is the first step towards behavioural change and lays the foundation for policy change. For example, if a high percentage of the population knew that $64 \%$ of all water goes to agriculture, but contributes little to the country's economic growth, an increase in irrigation tariffs would receive more public support" (MWI, 2009: 2-2). The goal is to have by 2022 a population "well aware of water scarcity and [about] the importance of conserving and protecting our limited water resources" (MWI, 2009: 8-1).

Even if both supply and demand side solutions are suggested by the strategy, the first chapter of the WfL shows that only with the construction of the RSDSC and Disi projects by 2022 there will be a water balance between supply and demand (MWI, 2009: ch.1). These two projects are portrayed as vital for the country, as emerges several times in the strategy (MWI, 2009: 4). In doing so, the strategy strongly backs these two projects. Even if the strategy suggests also demand side solutions, overall only with the adoptions of these two supply-oriented projects Jordan would manage not to be a water scarce country anymore. Demand side solutions present in the strategy are not fully implemented. In fact, when it comes to implementation, the supply side solutions are being implemented (the RSDSC "first phase" is in process, the Disi project is operational, dams have been constructed, wastewater treatment are being built), while demand side solutions are not all implemented yet (regulations on crops and subsidies removal have not been implemented); conservation type of solutions, such as awareness raising campaigns, are being promoted.

\section{The 2016-2025 national water strategy}

In 2015, the 2016-2025 strategy updated the WfL 2008-2022 strategy. As explained by the minister of the MWI El-Naser, the MWI updated the strategy because of: the 
completion of the Millennium Development Goals (MDGs) and the necessity to evaluate Jordan's performance and achievements; the launch of the SDGs; increasing water demand; "continued water scarcity"; the regional geopolitical context; and the need to secure water for all Jordanians (MWI, 2015: I).

Two important framings emerge from the updated strategy, namely the integrated water resources management (IWRM) concept of "an integrated approach", and the concept of sustainability and sustainable use of natural resources. The focus on IWRM emerges from the emphasis in the foreword of the strategy on the integrated approach and inter-linkages between the water sector and the other sectors in the country. The necessity to consider water in a holistic way is reiterated throughout the report by looking at the whole economic development of the country and not narrowly only at the water sector. This is supported by the global discourse of the water-energy-food (WEF) nexus and of the millennium development goals (MDGs) and sustainable development goals (SDGs) in driving towards this comprehensive approach. The whole third chapter is also dedicated to IWRM. The IWRM comprehensive approach, reinforced by the WEF nexus and the SDGs, is one instance in which the strategy is informed by global discourses. This is reinforced by the fact that the strategy builds on new developments in Jordan, including the "Nuclear Power Plan, Oil-shale and Red-Dead conveyance", pressure of Syrian refugees on the limited water resources, "effect of electricity and fuel increased prices", and the "fiscal strain affecting service delivery" (MWI, 2015: 2). Hence, the strategy aims at solving water scarcity and ensuring a resilient water sector by looking at water with an integrated and holistic approach. This is also shown by emphasising that this strategy is aligned with updated strategies adopted in other sectors, including the "National Energy Strategy 2007-2020" and the "Agricultural Document of 2009", restating again the necessity of looking at water in its relation to other sectors, in primis with agriculture and energy (ibid.).

The second prominent concept in the strategy is "sustainability", which is informed by the SDGs. This concept also includes and drives towards sustainable use of water resources, shaping policies concerning over-abstraction of groundwater resources. Sections 1.7 and 4.5 are dedicated to SDGs. On page 11 of the updated strategy, a Table explains that the goal is to decrease the over-abstraction from groundwater resources from $160 \mathrm{MCM}$ per year in 2015 to $118 \mathrm{MCM}$ per year in 2025; increase the use of surface water resources from $263 \mathrm{MCM}$ per year in 2015 to 
329 MCM per year in 2025; increase the use of treated wastewater from 140 MCM per year in 2015 to $235 \mathrm{MCM}$ per year in 2025; and a central role will be played by the additional resources - including desalination and the 2015 RSDSC /swap agreement that would increase water from $10 \mathrm{MCM}$ per year in 2015 to $260 \mathrm{MCM}$ per year in 2025.

The solutions clearly emerge from the table, and are mainly treated wastewater and desalination / swap with a regional dimension. So it could be said that while the updated water strategy promotes an integrated and holistic approach, informed by global emerging discourses, the sanctioned solutions - similarly to the previous strategy - focus on increasing the supply from desalination and treated wastewater. However, there is a growing attention to the necessity of using the groundwater resources in a sustainable way, and an imperative to reduce over-abstraction beyond the safe yield.

\section{Conclusion}

This article was guided by the following question How is water scarcity framed in the Jordanian water strategy, what are the causes emphasised, and what are the solutions identified? And in minor part also: How has this framing changed in the two versions of the national water strategy? The article found that the WfL strategy is very comprehensive, and includes all reasons for water scarcity identified by the latest literature. It is also holistic when it comes to solutions suggested. However, it also found that certain solutions - desalination, water swap, treated wastewater, RSDSC and the Disi - are particularly emphasised and sanctioned. This is also reflected in the solutions that are being implemented, mainly those that were sanctioned in the strategy.

The updated strategy, which is a response to the Syrian refugees crisis in Jordan, builds on WfL, and is therefore comprehensive concerning the causes of water scarcity and the solutions suggested. Both strategies, however, are constrained by the fact that most of the surface water resources in the country are of transboundary nature, and therefore by the water treaties governing the allocation of these waters. Nevertheless, the main difference between the two versions of the strategy is that the updated one is heavily informed by global discourses of IWRM, sustainable development and SDGs, including WEF nexus. Nevertheless, the solutions suggested and sanctioned are similar to the ones emphasised in the WfL. 
The solutions suggested and emphasised in both versions of the strategy are mainly technical engineering solutions aiming at increasing the supply - like desalination, the Disi, the RSDSC projects - or economic and market solutions. What is missing in both versions of the strategy is an analysis of how water is distributed in the society, who is benefiting from the current allocations, who is excluded, which ones are the marginalised groups. In fact, discussions of equity in access and allocation to water resources could have been further deepened. This is particularly striking in the WfL, as in the updated strategy general mention of the goal of providing water to "all Jordanians" is repeated several times, and it is also suggested that the strategy will outline "within the human rights framework". Nevertheless, a more detailed attention to the nuances of access to water in the country, capturing the differences that exist in different governorates and in different neighbourhoods within the same city, would have been useful. This could have been done by considering and adopting the concept of human dignity - giving higher relevance to SDG 10 in the strategy - in its relation to all water challenges and solutions. Nevertheless, while the updated strategy aims at securing water for all Jordanians - in line with the SDGs through an integrated approach and in a sustainable way, only the next decade will show us to what extent these important goals will be achieved, and how.

\section{Notes}

${ }^{1}$ For further literature on water politics and discourses in Jordan, please see: Hussein and Grandi (2015; 2017) and Hussein $(2017 \mathrm{a}, \mathrm{c} ; 2018 \mathrm{a})$ on the role of the broader context and discourses in shaping transboundary water governance; Hussein (2017b) on the role of the educational system and textbooks in constructing and reproducing the discourse of water scarcity; Hussein (2018b), Yorke (2013; 2016), Greenwood (2015), Keulertz (2013) on the water politics in Jordan, including on the concept of shadow state; and Hussein (2018c) on the construction of the discourse of water scarcity in Jordan.

\section{References}

DRYZEK, J.S., (1997). The politics of the earth: environmental discourses. Oxford, UK: Oxford University Press.

GREENWOOD, S. (2014). Water Insecurity, Climate Change and Governance in the Arab World. Middle East Policy, XXI. 
HUSSEIN, H. \& GRANDI, M. 2015. Contexts Matter: A Hydropolitical Analysis of Blue Nile and Yarmouk River Basins. Social Water Studies in the Arab Region

HUSSEIN, H. \& GRANDI, M. 2017. Dynamic political contexts and power asymmetries: the cases of the Blue Nile and the Yarmouk Rivers International Environmental Agreements: Politics, Law and Economics.

HUSSEIN, H. (2016). An analysis of the discourse of water scarcity and hydropolitical dynamics in the case of Jordan(Doctoral dissertation, University of East Anglia).

HUSSEIN, H. 2017a. Whose 'reality'? Discourses and hydropolitics along the Yarmouk River. Contemporary Levant,2(2), 103-115.

HUSSEIN, H. 2017b. A critique of water scarcity discourses in educational policy and textbooks in Jordan, The Journal of Environmental Education.

HUSSEIN, H. 2017c. Politics of the Dead Sea Canal: a Historical Review of the Evolving Discourses, Interests, and Plans. Water International, Vol. 42, issue 5

HUSSEIN, H. 2018a. Yarmouk, Jordan, and Disi basins: Examining the impact of the discourse of water scarcity in Jordan on transboundary water governance. Mediterranean Politics, 1-21.

HUSSEIN, H. 2018b. Tomatoes, tribes, bananas, and businessmen: An analysis of the shadow state and of the politics of water in Jordan. Environmental Science \& Policy, 84, 170-176.

HUSSEIN, H., 2018c, Lifting the veil: Unpacking the discourse of water scarcity in Jordan, Environmental Science \& Policy, 89, 385-392.

KEULERTZ, M., 2013. Drivers and Impacts of Farmland Investment in Sudan: Water and the Range of Choice in Jordan and Qatar. King's College, London.

MWI (2009). Water for Life. Jordan's Water Strategy 2008-2022.

MWI (2015). Water for Life. Jordan's Water Strategy 2016-2025.

YORKE, V. (2013). Politics matter: Jordan's path to water security lies through political reforms and regional cooperation. NCCR Trade Regulation, Working Paper 2013/19.

YORKE, V. (2016). Jordan's shadow state and water management: prospects for water security will depend on politics and regional cooperation. In SocietyWater-Technology (pp. 227-251). Springer International Publishing. 
